\title{
Combined proteomic/transcriptomic signature of recurrence post-liver transplantation for hepatocellular carcinoma beyond Milan
}

\author{
Mamatha Bhat ${ }^{1,2,3,7^{*}+}$ (D), Sergi Clotet-Freixas ${ }^{1,3 \dagger}$, Cristina Baciu ${ }^{1 \dagger}$, Elisa Pasini ${ }^{1}$, Ahmed Hammad ${ }^{1,4}$, \\ Tommy Ivanics ${ }^{5}$, Shelby Reid ${ }^{7}$, Amirhossein Azhie ${ }^{1}$, Marc Angeli ${ }^{1}$, Anand Ghanekar ${ }^{1,3,5}$, Sandra Fischer ${ }^{5}$, \\ Gonzalo Sapisochin ${ }^{1,6+}$ and Ana Konvalinka ${ }^{1,3,5,7,8,99^{*}}$
}

\begin{abstract}
Background and aims: Liver transplantation (LT) can be offered to patients with Hepatocellular carcinoma (HCC) beyond Milan criteria. However, there are currently limited molecular markers on HCC explant histology to predict recurrence, which arises in up to $20 \%$ of LT recipients. The goal of our study was to derive a combined proteomic/ transcriptomic signature on HCC explant predictive of recurrence post-transplant using unbiased, high-throughput approaches.

Methods: Patients who received a LT for HCC beyond Milan criteria in the context of hepatitis B cirrhosis were identified. Tumor explants from patients with post-transplant $\mathrm{HCC}$ recurrence $(N=7)$ versus those without recurrence $(\mathrm{N}=4)$ were analyzed by mass spectrometry and gene expression array. Univariate analysis was used to generate a combined proteomic/transcriptomic signature linked to recurrence. Significantly predictive genes and proteins were verified and internally validated by immunoblotting and immunohistochemistry.

Results: Seventy-nine proteins and 636 genes were significantly differentially expressed in HCC tumors with subsequent recurrence $(p<0.05)$. Univariate survival analysis identified Aldehyde Dehydrogenase 1 Family Member A1 (ALDH1A1) gene ( $H R=0.084,95 \% \mathrm{Cl} 0.01-0.68, p=0.0152), A L D H 1 A 1$ protein $(H R=0.039,95 \% C l 0.16-0.91$, $p=0.03)$, Galectin 3 Binding Protein (LGALS3BP) gene (HR=7.14,95\%Cl 1.20-432.96, $p=0.03)$, LGALS3BP protein $(H R=2.6,95 \% \mathrm{Cl} 1.1-6.1, p=0.036)$, Galectin 3 (LGALS3) gene $(H R=2.89,95 \% \mathrm{Cl} 1.01-8.3, p=0.049)$ and LGALS3 protein ( $\mathrm{HR}=2.6,95 \% \mathrm{Cl} 1.2-5.5, \mathrm{p}=0.015)$ as key dysregulated analytes in recurrent $\mathrm{HCC}$. In concordance with our proteome findings, HCC recurrence was linked to decreased ALDH1A1 and increased LGALS3 protein expression by Western Blot. LGALS3BP protein expression was validated in 29 independent HCC samples.
\end{abstract}

\footnotetext{
*Correspondence: Mamatha.Bhat@uhn.ca; Ana.Konvalinka@uhn.ca

${ }^{\dagger}$ Mamatha Bhat, Sergi Clotet-Freixas and Cristina Baciu contributed equally to this work

${ }^{\dagger}$ Gonzalo Sapisochin and Ana Konvalinka contributed equally to this work

${ }^{2}$ Division of Gastroenterology and Hepatology, University of Toronto, Toronto, Canada

9 University Health Network, 585 University Avenue, Room 11-PMB-189,

Toronto, ON M5G 2N2, Canada

Full list of author information is available at the end of the article
}

(c) The Author(s) 2021. Open Access This article is licensed under a Creative Commons Attribution 4.0 International License, which permits use, sharing, adaptation, distribution and reproduction in any medium or format, as long as you give appropriate credit to the original author(s) and the source, provide a link to the Creative Commons licence, and indicate if changes were made. The images or other third party material in this article are included in the article's Creative Commons licence, unless indicated otherwise in a credit line to the material. If material is not included in the article's Creative Commons licence and your intended use is not permitted by statutory regulation or exceeds the permitted use, you will need to obtain permission directly from the copyright holder. To view a copy of this licence, visit http://creativecommons.org/licenses/by/4.0/. The Creative Commons Public Domain Dedication waiver (http://creativeco mmons.org/publicdomain/zero/1.0/) applies to the data made available in this article, unless otherwise stated in a credit line to the data. 
Conclusions: Significantly increased LGALS3 and LGALS3BP gene and protein expression on explant were associated with post-transplant recurrence, whereas increased ALDH1A1 was associated with absence of recurrence in patients transplanted for HCC beyond Milan criteria. This combined proteomic/transcriptomic signature could help in predicting HCC recurrence risk and guide post-transplant surveillance.

Keywords: Hepatocellular carcinoma, Liver transplantation, Milan criteria, Proteome, Transcriptome, Combined signature, Tumor explant, Predictors of recurrence

\section{Introduction}

Hepatocellular carcinoma (HCC) is estimated to represent the fourth most common cause of cancer-related deaths globally [1]. Selected patients with early-stage HCC are candidates for liver transplantation (LT) as a curative therapy. HCC has even become the leading indication for LT worldwide in recent years [1,2]. Currently, the Milan criteria (one lesion less than $5 \mathrm{~cm}$ in diameter or three or fewer lesions, all below $3 \mathrm{~cm}$ ) remain the gold standard for defining the optimum tumor burden that determines transplant eligibility [3]. Nonetheless, it has been recognized that expanded selection criteria can afford patients excellent post-LT outcomes even when traditional morphologic tumor standards are exceeded [4]. Criteria have evolved by expanding the allowable tumor size and number to the incorporation of alphafetoprotein (AFP) and histologic differentiation [4-9]. The safe expansion of selection criteria for LT in HCC hinges on an improved understanding of tumor biology through surrogate markers [1]. Consequently, such expanded criteria may allow extending the use of LT as a curative-intent treatment option to a greater number of patients, especially considering that HCC biology and progression are patient-dependent.

Numerous studies have tried to identify molecular biomarkers that predict HCC recurrence after LT or resection [10-18]. In this context, proteomic analysis of liver tissue from HCC patients has recently identified some proteins such as melanoma-associated antigen genes [19] and cytokeratin-19 [20]; their expression correlated with early recurrence of HCC post-hepatectomy and allowed stratification into various subtypes with distinct clinical outcomes [11]. Whether such proteomic signatures can stratify patients in a diverse HCC LT population that exceeds Milan criteria is unclear. Identifying novel molecular signatures may enable the selection of patients exceeding traditional standards who may still benefit from LT. Also, signature proteins related to distinct tumor subtypes may potentially serve as actionable targets for individualized prevention and therapy.

We hypothesized that genes and proteins shared among HCC tumors on explant could be used to predict recurrence. Therefore, the goal of the present study was to define a combined proteomic/transcriptomic signature predictive of recurrence post-transplant in patients transplanted for HCC beyond Milan criteria, based on the molecular profiling of the dominant tumour on explant.

\section{Methods \\ Patient population}

Patients who underwent LT for hepatitis B-induced HCC beyond Milan criteria between 2004 and 2015 were included in our study. This protocol was approved by the University Health Network (UHN) Institutional Review Board (REB\#15-9989). Those with recurrence were matched for age and sex to those without recurrence by at least 2 years post-transplant. The first set of patients $(n=11)$ had snap-frozen HCC explant samples in the biobank, meeting inclusion criteria, and was therefore eligible for proteome and transcriptome analysis. An additional set of 29 samples meeting the above inclusion criteria were from patients with only archived formalinfixed, paraffin-embedded samples available, on which only immunohistochemistry (IHC) validation was feasible. Characteristics of the tumors on explant, including size and number of tumors, microvascular invasion and associated AFP at the time of transplant were documented. Patients could have received bridging therapy but needed to have a viable tumor on the explant for the purposes of this analysis.

\section{Hepatocellular carcinoma sample preparation for mass spectrometry}

Frozen HCC tissue samples obtained from the UHN biobank were processed and analyzed in a blinded fashion. These represented the largest, viable tumor in the explant. Rapigest detergent $(0.2 \%)$ was added to each piece of tissue ( $100 \mathrm{mg}$ in weight). Samples were then homogenized using microbeads in a tissue dissociator. Ammonium bicarbonate was added, and samples were subjected to sonication (10 s, 3 times) on ice. Samples were then centrifuged at $15,000 \mathrm{~g}$ at $4{ }^{\circ} \mathrm{C}$ for $20 \mathrm{~min}$. Supernatant was collected and vortexed. Total protein concentration was determined using the micro-BCA protein assay kit (Thermo). Each sample was then normalized to $250 \mu \mathrm{g}$ of total protein. Samples were denatured at $80{ }^{\circ} \mathrm{C}$ for $15 \mathrm{~min}$, followed by reduction in $10 \mathrm{mM}$ 
dithiothreitol (final concentration) for $15 \mathrm{~min}$ at $65{ }^{\circ} \mathrm{C}$ and alkylation in $20 \mathrm{mM}$ (final concentration) iodoacetamide for $40 \mathrm{~min}$ in the dark at room temperature. Finally, trypsin (Promega) was added at 1:50 w/w and incubated overnight at $37^{\circ} \mathrm{C}$. Digested samples were acidified with trifluoroacetic acid $(1 \% \mathrm{v} / \mathrm{v})$ and vortexed for $1 \mathrm{~min}$, then left at room temperature for $5 \mathrm{~min}$. Samples were centrifuged at $15,000 \mathrm{~g}$ for $10 \mathrm{~min}$ to remove Rapigest, then transferred into the new tubes and frozen at $-20{ }^{\circ} \mathrm{C}$ until further analysis [21, 22]. Following digestion and removal of Rapigest, strong cation exchange (SCX) chromatography and fractionation were performed on an HPLC system (Agilent 1100) using a 60-min two-step gradient. The resulting fractions corresponding to chromatographic peaks of eluting peptides were pooled into 10 fractions. Peptides from each fraction were extracted, desalted and diluted to $41 \mu \mathrm{L}$ with $0.1 \% \mathrm{v} / \mathrm{v}$ formic acid in MS-grade pure water.

\section{Tandem mass spectrometry (MS/MS)}

Samples were randomized and subjected to mass spectrometry (MS) on a Thermo Scientific EASY-nLC1000 system, coupled to a Q-Exactive Plus hybrid quadrupoleorbitrap mass spectrometer using a nano-electrospray ionization source (Thermo Scientific) [21-23]. For each HCC sample, $18 \mu \mathrm{L}$ of eluted peptides were injected onto a $3.3 \mathrm{~cm} \mathrm{C18} \mathrm{pre-analytical} \mathrm{column} \mathrm{(IntegraFrit} \mathrm{capillary,}$ New Objective; inner diameter: $75 \mu \mathrm{m}$; bead size: $5 \mu \mathrm{m}$; Agilent Technologies) followed by a $\mathrm{C} 18$ resolving analytical column (PicoTip emitter, inner diameter: $15 \mathrm{~cm} \times$ $75 \mu \mathrm{m}$; tip: $8 \mu \mathrm{m}$ tip; bead size: $3 \mu \mathrm{m}$; Agilent Technologies). Samples were run on a 60 -min gradient of increasing concentrations of Buffer B (100\% acetonitrile) in 0.1\% formic acid/99.9\% MS grade water (Thermo Scientific). The method started at $1 \%$ Buffer B, and the concentration was increased to $5 \%$ at $2 \mathrm{~min}$, with increases to $35 \%$ (49 $\mathrm{min}), 65 \%$ (52 $\mathrm{min}$ ) and 100\% (53 min). The spectra were obtained under data-dependent acquisition mode, consisting of full MS1 scans (m/z range: 400-1500; resolution: 70,000) followed by MS2 scans of the top 15 parent ions (resolution: 17,500).

\section{Protein identification and quantification}

For protein identification, the RAW files of each MS run were generated by XCalibur software v3.0.63 (Thermo Scientific). Raw data were analyzed by MaxQuant software (version 1.5.3.28) and searched against the human Uniprot FASTA database (HUMAN5640_sProt-072016, update of July 20,2016). Proteins and peptides were identified with a false discovery rate of $1 \%$. A minimum length of 6 amino acids was selected. The false positive rate was determined using reversed mode. Trypsin/P was selected as digestion enzyme, and a maximum of 2 missed cleavages was enabled. While cysteine carbamidomethylation was selected as a fixed modification, methionine oxidation and $\mathrm{N}$-terminal acetylation were set as variable modifications. The initial peptide tolerance against a 'human-first-search' database was set to $20 \mathrm{ppm}$. The main search peptide mass tolerance was $40 \mathrm{ppm}$, and the fragment mass MS/MS tolerance was 0.5 Da. Matching between runs was selected. Normalized label-free quantification (LFQ) of proteins was derived from extracted ion current information from razor and unique peptides with a minimum ratio count of 1 . The mass spectrometry proteomics data have been deposited to the ProteomeXchange Consortium via the PRIDE [24] partner repository with the dataset identifier PXD022881 (Reviewer account details: Username: reviewer_pxd022881@ebi. ac.uk; Password: 2GmXJTJo).

Proteomics data were analyzed using Perseus software (version 1.5.2.6). Reverse hits and contaminants were manually checked and removed. Distribution of log2transformed LFQ intensity values of all quantified proteins was examined for each sample (Additional file 1: Fig. $\mathrm{S} 1 \mathrm{~A}$ ). Following exclusion of proteins identified in $<50 \%$ of the samples, we subjected the zero-value intensities to imputation (assuming that low abundance values were missing), keeping a normal distribution, with a downshift of 1.8 standard deviations, and a width of 0.5 for each sample (Additional file 1: Fig. S1B). After imputation, we determined the differentially expressed proteins between recurrent and non-recurrent HCC samples by comparing their mean log2-transformed LFQ intensities using the two-tailed independent $t$-test $(P<0.05)$, followed by Benjamini-Hochberg adjustment. Principal component analysis was performed in Perseus. Two components that explained the most variability in samples were selected. Finally, pathway analysis was performed on significantly differentially expressed proteins, using pathDIP (http:// ophid.utoronto.ca/pathDIP/) [25].

\section{Gene expression analysis}

RNA was extracted from snap-frozen HCC explant tumor specimens and purified using RNeasy Mini Kit (Qiagen; Hilden, Germany). RNA quality was verified by Nanodrop spectrophotometer (VWR; Radnor, PA) and Bioanalyzer (Agilent; Santa Clara, CA). Gene expression microarray analysis was performed using the Affymetrix Human Gene 2.0 ST platform (Thermo Fisher, Waltham, MA). The initial cohort included eleven samples, but two of them did not pass the quality control filter required for microarray processing, therefore the remaining nine were used for further analysis. We compared gene expression of the explant HCC specimens between those who developed recurrence $(n=6)$ versus those who did not develop recurrence $(n=3)$. 
Microarray data were pre-processed (background subtraction and quantile normalization) by Robust Multi-array Average (RMA) utilizing the oligo package in $\mathrm{R}$ version 3.6 [26]. Gene annotation was done using pd.hugene.2.0.st annotation files [27]. Statistical analysis was performed with limma package [28]. After having fit the model with lmFit function (linear model), the differential gene expression was calculated using eBayes function (moderated t-test, p-value, B stats). A gene was considered differentially expressed between the two groups if $\mathrm{p}$-value $<0.05$. In addition, filtering criteria by fold change (FC) was selected: $\mathrm{FC} \geq 2$ (upregulation) or $\mathrm{FC} \leq 0.5$ (downregulation).

For identification of protein-protein interactions and pathways in explant HCC that were predictive of HCC recurrence, we analyzed the common significant genes/proteins separately for the two groups using STRING software, version 10.5 (https://string-db.org). The transcriptomic data have been deposited to Gene Expression Ominibus (GEO) repository with the dataset identifier GSE164368.

\section{Protein expression analysis by Western Blot}

For validation purposes, we selected only those proteins in common with corresponding differentially expressed genes, namely Galectin 3 (LGALS3), Galectin 3 Binding Protein (LGALS3BP), and Aldehyde Dehydrogenase 1 Family Member A1 (ALDH1A1), that were significantly associated with the time of recurrence by univariate analysis, as described in the statistical analysis section.

We measured protein expression by Western blot in the same human HCC tissue samples used for proteome analysis. Protein concentration was determined using a micro-BCA protein assay kit (Thermo). To verify changes in LGALS3, LGALS3B and ALDH1A1 protein expression, $10 \mu \mathrm{g}$ of total protein were loaded onto $10 \%$ acrylamide gels, separated by SDS-PAGE, and transferred to a PVDF membrane (Millipore). Membranes were then blocked with 5\% milk and incubated with mouse monoclonal anti-LGALS3 (1:4000; ab2785, Abcam, previously characterized [29]) or rabbit polyclonal anti-ALDH1A1 (1:2000; ab227948, Abcam [30]). Incubation with rabbit polyclonal anti-LGALS3BP (HPA000554, Atlas Antibodies) did not result in a specific band. Control for protein loading was performed by reblotting membranes using a mouse monoclonal antibody for GAPDH (CB1001, Sigma). The secondary antibodies were HRP-conjugated anti-rabbit (A0545, Sigma) and anti-mouse (P0447, Dako). Following detection in a Gel-Imaging System (Bio-rad), bands were quantified by densitometry using Image J software.

\section{Immunohistochemistry}

Protein expression of LGALS3BP was examined by immunohistochemistry on the first set of patients $(\mathrm{n}=11)$, with snap-frozen samples in the biobank meeting inclusion criteria (Table 1). LGALS3BP protein expression was also studied in an additional, independent set of 29 patients (Additional file 8: Table S6). Sections $(4 \mu \mathrm{m})$ from formalin-fixed paraffin-embedded samples were treated for antigen retrieval following manufacturer's instructions. Rabbit anti-LGALS3BP (Human Protein Atlas, HPA000554) was used at a dilution of 1:500 as primary antibody. After incubation with an HRP-conjugated anti-rabbit secondary antibody, the antibody-HRP complex was visualized with hydrogen peroxide substrate and 3,3'-diaminobenzidine tetrahydrochloride $(\mathrm{DAB})$ chromogen. Slides were then counterstained with Harris Hematoxylin. Entire slides were then digitally scanned in an Aperio ScanScope CS scanning system and analyzed by Aperio Image Scope Viewer software (Leica Biosystems Imaging, Inc, CA) using the Positive Pixel Count v9 algorithm. The intensity of the strongly positive pixels was quantified in each area and normalized to the $\mu \mathrm{m}^{2}$ of area analyzed. The strongly positive intensity $/ \mu \mathrm{m}^{2}$ across all areas were then averaged to determine LGALS3BP protein expression in each HCC sample.

\section{Examination of top candidates in an independent $\mathrm{HCC}$ dataset}

Several molecules that significantly differentiated recurrent from non-recurrent samples at both gene and protein level (ALDH1A1, LGALS3, LGALS3B) were selected for further investigation. In order to examine their prognostic potential, we analyzed HCC tumors from The Cancer Genome Atlas (TCGA) using KMplotter, a webbased tool that enables survival analysis across multiple cancers and datasets. These tumors represented hepatectomy specimens and not HCC explant samples. Patient samples were split into two groups according to software cut-off for ALDH1A1 (RNAseq probe\#216), LGALS3 (RNAseq probe\#3958), and LGALS3BP (RNAseq probe\#3959). We ran multivariate survival analysis based on the high versus low expression of each of the three genes in tumors. The two groups were compared by a Kaplan-Meier survival plot, and the hazard ratio with $95 \%$ confidence intervals and log-rank p-value were calculated.

\section{Statistical analysis}

Distributions of Western Blot ratios (LGALS3/GAPDH, ALDH1A1/GAPDH, and LGALS3/ALDH1A1) and LGALS3BP positive staining values were examined using 
Table 1 Clinical characteristics of the patients transplanted for HCC beyond Milan criteria with versus without recurrence posttransplant

\begin{tabular}{|c|c|c|c|}
\hline Variable & Non-recurrent group $(n=4)$ & Recurrent group $(n=7)$ & $P$ value \\
\hline \multicolumn{4}{|l|}{ Preoperative factors } \\
\hline Mean age (range), y & $64(58-71)$ & $55(46-61)$ & 0.009 \\
\hline Sex, no. of men (\%) & $4(100)$ & $6(85.7)$ & 1.000 \\
\hline Race, $n(\%)$ & & & 0.730 \\
\hline Caucasian & 0 & 1 & \\
\hline Asian & 3 & 5 & \\
\hline \multicolumn{4}{|l|}{ Black } \\
\hline \multicolumn{4}{|l|}{ Hispanic } \\
\hline \multicolumn{4}{|l|}{ Native American } \\
\hline Other/unreported & 1 & 1 & \\
\hline Clinical CPT score before transplant, $n(\%)$ & & & 0.491 \\
\hline A & 4 & 5 & \\
\hline B & 0 & 2 & \\
\hline C & 0 & 0 & \\
\hline Clinical MELD score at transplant, median (range) & $9(8-9)$ & $9(8-13)$ & 0.323 \\
\hline Bridging/downstaging LRT & & & 0.509 \\
\hline 1. SIRT & 0 & 0 & \\
\hline 2. RFA & 3 & 2 & \\
\hline 3. TACE & 0 & 3 & \\
\hline 4. PEIT & 1 & 1 & \\
\hline 5. Combined & 0 & 0 & \\
\hline AFP, median (range), at the time of transplant $(\mu \mathrm{mol} / \mathrm{L})$ & $3(3-48)$ & $68(5-20,303)$ & 0.453 \\
\hline Waiting list time (time to LT), median (range), months & $4(2-5)$ & $5(2-7)$ & 0.407 \\
\hline \multicolumn{4}{|l|}{ Intraoperative factors } \\
\hline Cold ischemia time, median (range), minutes & $327(301-470)$ & $421(275-761)$ & 0.212 \\
\hline Warm ischemia time, median (range), minutes & $44(42-55)$ & $44(37-53)$ & 0.414 \\
\hline Estimated blood loss, median (range), mL & $1070(230-2100)$ & $1500(1000-2800)$ & 0.253 \\
\hline \multicolumn{4}{|l|}{ Pathologic factors } \\
\hline Weight of explanted liver, median (range), (g) & $766(750-1650)$ & $1005(936-1059)$ & 0.804 \\
\hline Largest tumor diameter (cm), mean \pm SD (range) & $3.5 \pm 0.6$ & $4.6 \pm 1.8$ & 0.156 \\
\hline Number of lesions on explant, median (range) & $5(5-9)$ & $7(1-20)$ & 0.323 \\
\hline Capsular invasion (yes), n (\%) & 0 & $3(43 \%)$ & 0.236 \\
\hline Satellite nodules, (yes) (\%) & 0 & $2(29 \%)$ & 0.491 \\
\hline HCC histologic grade & & & 1.000 \\
\hline Moderately differentiated & $4(100 \%)$ & $6(86 \%)$ & \\
\hline Well-differentiated & 0 & $1(14 \%)$ & \\
\hline Presence of microvascular invasion on the explant (\%) & $1(25 \%)$ & $4(57 \%)$ & 0.546 \\
\hline Major vessel invasion & 0 & $1(14 \%)$ & 1.000 \\
\hline Bile duct invasion & 0 & 0 & 1.000 \\
\hline Portal vein invasion & 0 & 0 & 1.000 \\
\hline \multicolumn{4}{|l|}{ HCC-related outcome } \\
\hline Vital status & & & 0.109 \\
\hline Alive & 2 & 0 & \\
\hline Dead & 2 & 7 & \\
\hline Overall survival, (years) & $6(0-11)$ & $3(1.2-7.5)$ & 0.261 \\
\hline Time to recurrence, (months) & N/A & $12(3-24)$ & \\
\hline
\end{tabular}

Count and median values are reported, with the $95 \%$ confidence intervals displayed in the brackets

Significant $P$ value is in bold italic

AFP alpha fetoprotein, CPT child-Pugh score, HCC hepatocellular carcinoma, LRT locoregional treatment, $L T$ liver transplant, $P E I T$ percutaneous ethanol injection therapy (alcohol ablation), MELD model for end-stage liver disease, RFA radiofrequency ablation, SD standard deviation, SIRT selective internal radiotherapy, TACE trans-arterial chemoembolization 
the Shapiro-Wilks normality test. We assessed differences between groups using the independent $\mathrm{t}$-test for variables following a normal distribution, and the Wilcoxon-Mann-Whitney non-parametric test for variables not following a normal distribution. Pearson correlation coefficients were calculated between Western Blot and $\log 2$-transformed LFQ protein intensity values of a particular protein, and between log2-transformed LFQ protein intensity values of different proteins of interest, using GraphPad Prism 8.0. Immunohistochemistry results were analyzed using unpaired $\mathrm{t}$-test. $\mathrm{P}<0.05$ was considered significant. Data are reported as median values with interquartile range. We investigated the association of selected significant genes, proteins or clinical characteristics with the time to recurrence, at the univariate level, with the coxph function of the survival package [31] in $R$ version 3.6. Using the same package, we plotted KaplanMeier survival curves, the statistical difference between the curves being calculated with survdiff function.

\section{Results \\ Proteome analysis of recurrent and non-recurrent HCC cases}

Patient characteristics are summarized in Table 1 . The study included $4 \mathrm{HCC}$ cases with no recurrence and 7 cases with recurrence post-LT. Tumors showed moderate differentiation and the number of lesions was comparable in the two groups ( $n=4$ for non-recurrent, and $n=7$ for recurrent). The non-recurrent group showed a lower frequency of microvascular invasion (25\% of patients) than the recurrent group (57\% of patients). Overall survival differed between the two groups, with a median of 6 years in non-recurrent patients and 3 years in recurrent patients.

We first analyzed the proteome of HCC explants (Fig. 1A). We identified and quantified a total of 6382 proteins $(\mathrm{FDR}<0.01)$ from $11 \mathrm{HCC}$ samples, using unbiased LC-MS/MS followed by label-free quantification (Fig. 1B). After removal of false-positive (reverse) hits and contaminants, 6277 proteins were further analyzed. In both study groups, the total numbers of identified proteins per sample were comparable and evenly distributed (Additional file 5: Table S1, Additional file 1: Fig. S1A, B). We next excluded from further analysis those proteins identified in $<6$ samples, which resulted in 4505 proteins identified and quantified in at least 6 samples. The median number of proteins identified per sample was 4073, after filtering (Additional file 5: Table S1). Our 4505 proteins demonstrated bell-shaped distribution (Additional file 1: Fig. S1A) in each sample. We thus imputed missing protein values from a normal distribution and assumed low abundance (Additional file 1: Fig. S1B). Principal component analysis using all 4505 proteins illustrated that while most recurrent and non-recurrent samples were correctly separated using protein expression data, sample 10 was the most distinct sample (Additional file 1: Fig. S1C). We finally identified 79 proteins that were significantly differentially expressed between recurrent and non-recurrent samples $(\mathrm{p}<0.05)$, with 44 proteins increased and 35 proteins decreased in recurrent samples (Additional file 1: Fig. 1C, Additional file 6: Table S2). We focused on proteins LGALS3BP (recurrent/non-recurrent fold change $=5.8, p=0.025$ ), member of the beta-galactosidebinding proteins that modulate cell-cell and cell-matrix interactions and LGALS3, a galectin/carbohydrate binding protein (recurrent/non-recurrent fold change $=2.3$, $\mathrm{p}=0.042$ ), among the proteins significantly increased in recurrent samples. We also focused on ALDH1A1 (recurrent $/$ non-recurrent $=0.2, p=0.048$ ), which was significantly decreased in recurrent samples. ALDH1A1 is an enzyme member of the aldehyde dehydrogenase family involved in alcohol metabolism. These proteins were selected because of their concomitant significant upregulation at the gene expression level [32-34]. Additionally, we noted that these proteins were identified confidently, with many unique peptides, and their expression levels correlated. Levels of ALDH1A1 negatively and significantly correlated with the levels of LGALS3 (Additional file 2: Fig. S2A), while the protein levels of LGALS3 and LGALS3BP showed a positive and significant correlation with each other (Additional file 2: Fig. S2B). Among the 79 proteins differentially expressed in recurrent vs nonrecurrent cases, 21 pathways were significantly enriched (adj. p < 0.05) (Additional file 7: Table S3). Most proteins, including LGALS3BP and LGALS3, belonged to the "immune system" and "innate immune system" based on pathway analysis.

\section{Transcriptome analysis of recurrent and non-recurrent HCC cases}

A total of 636 genes were significantly differentially expressed between the same recurrent compared to nonrecurrent HCC samples. We first examined those genes that were also significantly increased at the protein level in recurrent HCC. Sixty-eight upregulated genes and 44 upregulated proteins were identified in HCC explants associated with post-transplant recurrence, with five molecules in alignment with our proteome findings (Fig. 2). The common genes/proteins increased in recurrent HCC were significantly associated with cancer signaling pathways including PI3K-Akt signaling pathway $(\mathrm{p}=0.002)$ and Ras signaling pathway $(\mathrm{p}=0.010)$ (Additional file 8: Table S4), as well as TGF- $\beta$ signaling pathway $(\mathrm{p}=0.0099)$ and extracellular matrix $(\mathrm{ECM})$ receptor interaction $(p=0.0099)$. Metabolic pathways 


\section{A}

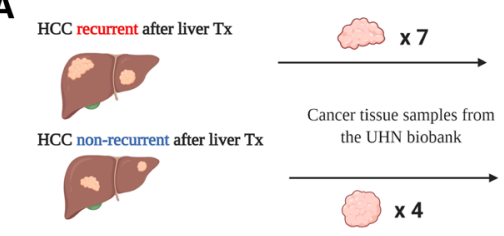

Proteins signficantly

increased in
recurrent HCC

$p<0.05$

Proteins signficantly
increased in

non-recurrent HCC

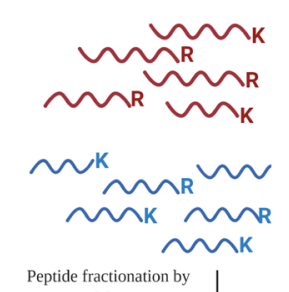

Peptide fractionation by
SCX

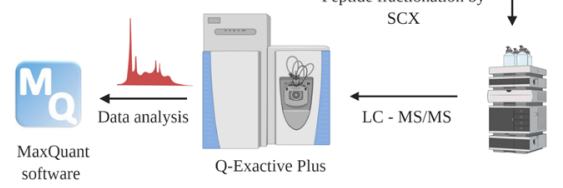

B

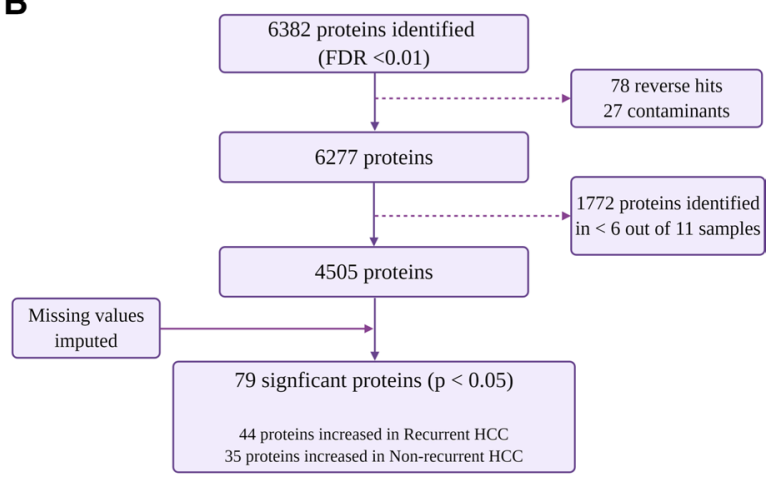

C

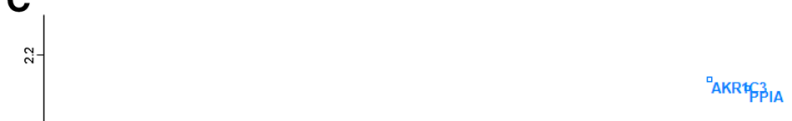

"PRPSAP2

${ }^{\mathrm{N} Q O 2}$

'GLUL HIP1R

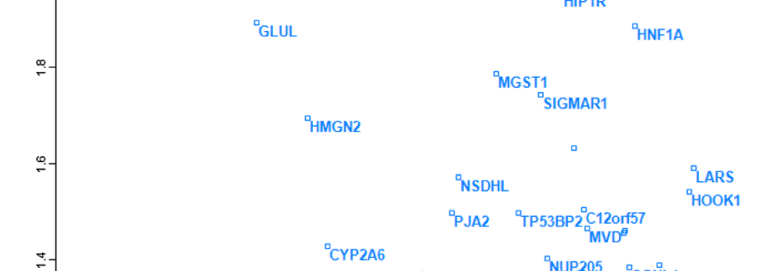

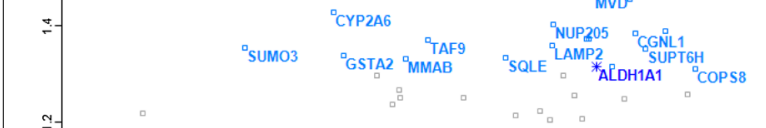

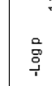<smiles>C1CCC1</smiles>
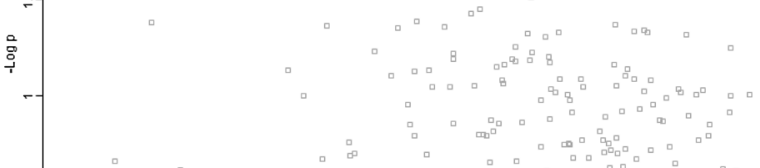

-

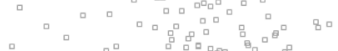

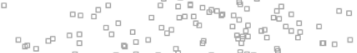

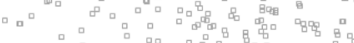

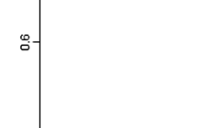

s.-

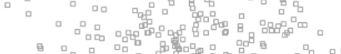

5

.

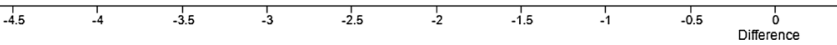

Fig. 1 Proteomics workflow and analysis of recurrent and non-recurrent hepatocellular carcinoma (HCC) tumour explant samples obtained at the time of transplantation. A Schematic diagram of the proteomics workflow including the $11 \mathrm{HCC}$ samples. B Proteomics analysis workflow to identify the most significant proteins between recurrent and non-recurrent HCC. C Volcano plot illustrating proteins differentially expressed $(p<0.05)$ in recurrent vs non-recurrent HCC tumors. Proteins in red are significantly increased in recurrent, while those in blue are significantly decreased in the recurrent cases. The three proteins bolded and marked with stars (ALDH1A1, LGALS3 and LGALS3BP) were subsequently selected for validation. Some protein names were removed for clarity, to minimize overlap. HCC, hepatocellular carcinoma; SCX, strong cationic exchange; LC, liquid chromatography; MS/MS, tandem mass spectrometry; ALDH1A1, retinal dehydrogenase 1, LGALS3, galectin-3; LGALS3BP, galectin-3-binding protein 


\title{
Significantly increased proteins in samples from patients that developed recurrence post-LT
}

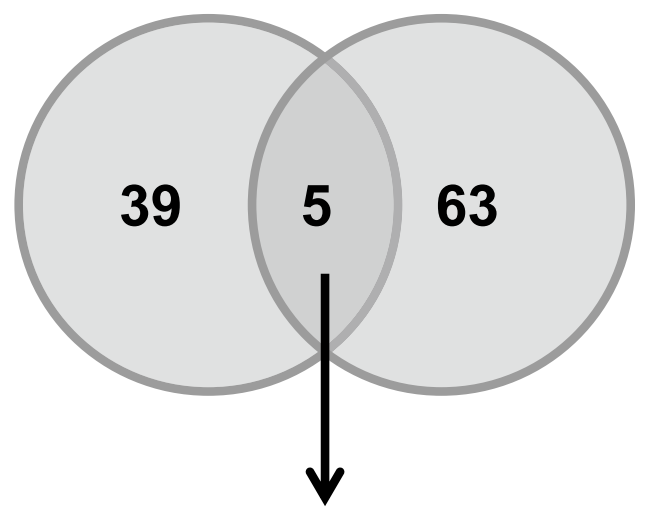

\author{
Significantly \\ increased \\ genes in \\ samples from \\ patients that \\ developed \\ recurrence \\ post-LT
}

\begin{tabular}{|c|c|c|c|}
\hline Protein/Gene & Description & $\mathbf{P}_{\text {proteins }} /$ FC & $\mathbf{P}_{\text {genes }}$ / FC \\
\hline HAL & histidine ammonia-lyase & $0.0197 / 3.09$ & $0.0076 / 7.48$ \\
\hline THBS1 & thrombospondin 1 & $0.0439 / 3.35$ & $0.0116 / 4.20$ \\
\hline LGALS3BP & galectin-3 binding protein & $0.0256 / 5.84$ & $0.0039 / 3.40$ \\
\hline BLMH & bleomycin hydrolase & $0.0474 / 4.01$ & $0.0076 / 2.78$ \\
\hline LGALS3 & galectin-3 & $0.0423 / 2.32$ & $0.0414 / 2.51$ \\
\hline
\end{tabular}

Fig. 2 Common proteins and genes significantly increased in HCC tumour explants obtained the time of transplant and exhibiting post-transplant recurrence. The Venn diagram illustrates the overlap between proteins and genes significantly increased in HCC tumour explant samples from patients that developed recurrence post-LT. HCC, hepatocellular carcinoma; LT, liver transplant; FC, fold change of the mean gene expression in recurrent samples, compared to non-recurrent

$(\mathrm{p}=2.10 \mathrm{E}-06), \quad$ Steroid biosynthesis $\quad(\mathrm{p}=3.70 \mathrm{E}-05)$, Fatty acid degradation $(\mathrm{p}=0.0003)$ and Glycolysis/Gluconeogenesis $(p=0.0008)$ were the most significantly enriched, as determined by the common elements $(n=6)$ of the genes $(n=175)$ and proteins $(n=35)$ significantly decreased in recurrent HCC (Additional file 8: Table S5, Fig. 3).

\section{ALDH1A1, LGALS3, and LGALS3BP are predictors of HCC recurrence}

Molecules that significantly differentiated recurrent and non-recurrent samples at both gene and protein level, together with the selected clinical variables (Table 2) were investigated at univariate level. High levels of the ALDH1A1 gene and protein were negatively associated with the HCC recurrence. On the other hand, both LGALS3BP and LGALS3 gene and protein levels were positively associated with HCC recurrence (Fig. 4). Except for age, no other clinical variable, including the RETREAT score that was developed for the HCC within Milan patients, was predictive for $\mathrm{HCC}$ recurrence. We noted that the RETREAT score was not significantly different between patients with recurrent HCC vs nonrecurrent $(p$-value $=0.068$ ). In addition, we plotted survival curves using the mean value as cut-off (Additional file 3: Fig. S3). The results show that ALDH1A1 protein,
LGALS3 protein and LGALS3BP gene were still significantly associated with HCC non-recurrence. Due to small sample size, we did not perform multivariable analysis.

\section{Verification and validation of ALDH1A1, LGALS3 and LGALS3BP changes in recurrent and non-recurrent HCC}

We employed Western Blot to confirm the observed changes in the protein expression of ALDH1A1, LGALS3 and LGALS3BP. Unfortunately, the antibody against LGALS3BP did not generate a single clear band, forcing us to focus on the first two proteins. In keeping with our proteomics findings, ALDH1A1 protein expression was numerically increased in non-recurrent samples $(\mathrm{P}=0.085$; Fig. $5 \mathrm{~A}, \mathrm{~B})$, while LGALS3 expression was significantly increased in recurrent samples $(\mathrm{P}=0.027$; Fig. 5A, C). Reassuringly, there was a strong, significant, and direct correlation between protein intensity levels of ALDH1A1 and LGALS3 measured by mass spectrometry, and their corresponding protein expression by Western Blot $(\mathrm{R}=0.837, \mathrm{P}=0.001$ for ALDH1A1; $\mathrm{R}=0.745$, $\mathrm{P}=0.008$ for LGALS3; Fig. 5D). Moreover, mass spectrometry intensity levels of ALDH1A1 negatively and significantly correlated with mass spectrometry levels of LGALS3 $(\mathrm{R}=-0.838, \mathrm{P}=0.001$; Additional file 2 : 


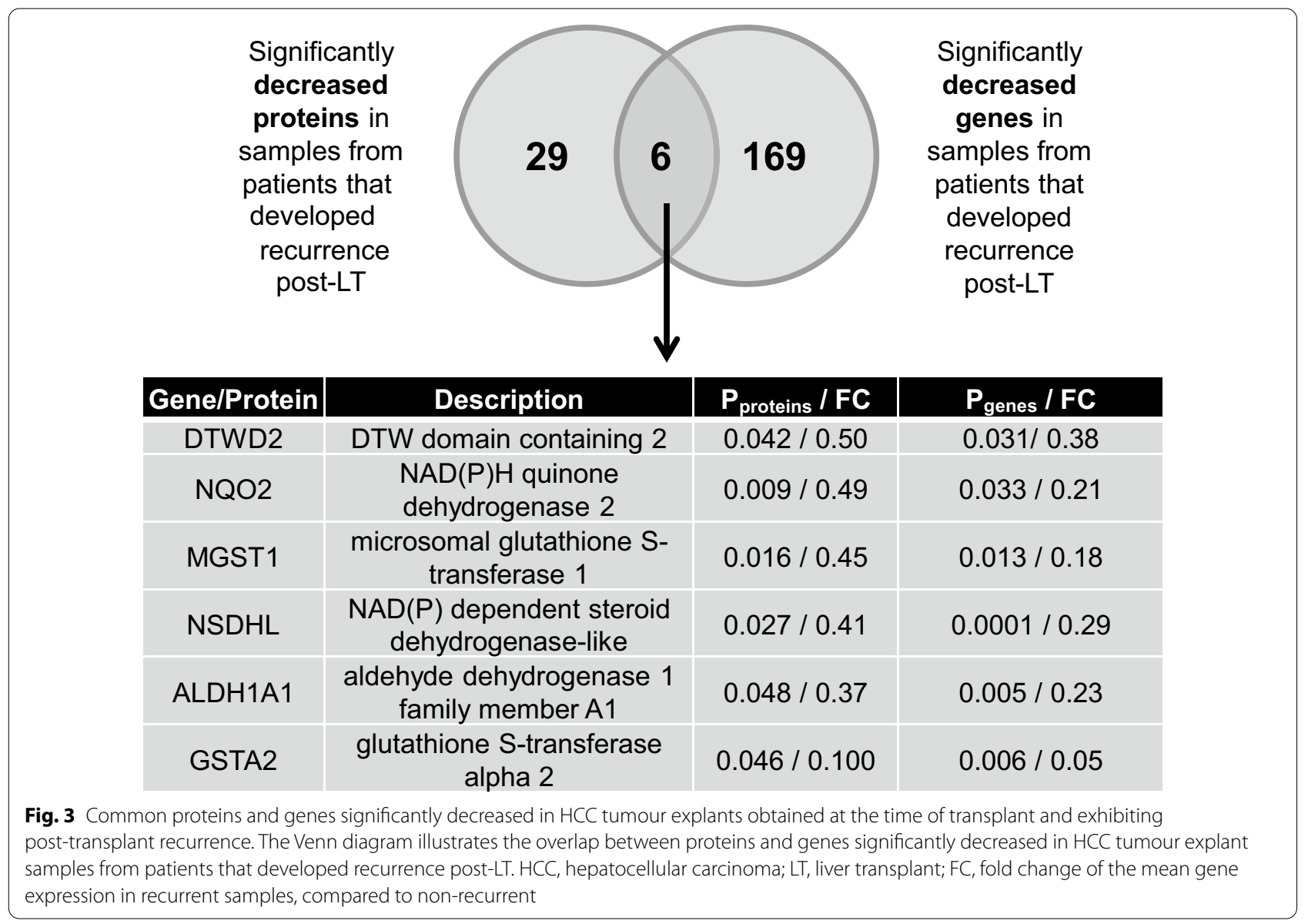

Fig. S2A). Since ALDH1A1 and LGALS3 were differentially expressed in opposite directions between recurrent and non-recurrent samples, we evaluated the LGALS3/ ALDH1A1 ratio. Importantly, we observed a $>20$-fold significant increase in the LGALS3/ALDH1A1 Western Blot ratio in recurrent, as compared to non-recurrent samples $(\mathrm{P}=0.012$; Fig. $5 \mathrm{E})$.

We next employed immunohistochemistry to confirm the observed changes in the protein expression of LGALS3BP. In concordance with our observations at the proteome and transcriptome level, LGALS3BP positive staining was numerically increased in recurrent HCC tumor explants, compared to non-recurrent, when examining the 11 samples from our discovery cohort (Fig. 6A). Reassuringly, increased LGALS3BP staining was also observed among recurrent cases in an independent, internal cohort of 29 LT recipients with HCC beyond Milan criteria (Fig. 6B).

\section{Examination of top candidates in an independent HCC dataset}

The impact of ALDH1A1, LGALS3 and LGALS3BP gene expression on overall survival was analyzed using the TCGA HCC dataset of 364 patients with HCC. ALDH1A1 was significantly predictive of overall survival in HCC patients, with a hazard ratio of $0.66(95 \% \mathrm{CI}$ $0.46-0.95$, logrank $\mathrm{p}=0.024)$ being associated with high expression level (Additional file 4: Fig. S4A). In contrast, increased LGALS3 expression (Additional file 4: Fig. S4B) was associated with an increased likelihood of death, with a hazard ratio of 1.59 (95\%CI 1.09-2.3, logrank $\mathrm{p}=0.014)$. Similarly, high expression of LGALS3BP (Additional file 4: Fig. S4C) was associated with increased likelihood of death, with a hazard ratio of 1.36 (95\% CI 0.94-1.97), although below significance threshold $(\operatorname{logrank} \mathrm{p}=0.1)$. These findings in the independent dataset suggest that the expression of ALDH1A1, LGALS3 and LGALS3BP may be indicative of the aggressiveness of $\mathrm{HCC}$, and thus its inherent propensity to recur post-transplant.

\section{Discussion}

We have delineated a set of proteins/genes on liver explant predictive of recurrence post-transplant, in patients transplanted for HCC beyond Milan. We found that expression levels of 3 specific proteins and their 
Table 2 Univariate analysis of the top proteins and genes differentially expressed in HCC explants and key clinical characteristics, as predictors of HCC recurrence post-transplant

\begin{tabular}{|c|c|c|}
\hline Variable & HR $(95 \% \mathrm{Cl})$ & $p$-value \\
\hline DTWD2 (protein) & $0.15(0.032-0.69)$ & 0.014 \\
\hline LGALS3 (protein) & $2.6(1.2-5.5)$ & 0.015 \\
\hline ALDH1A1 (gene) & $0.084(0.01-0.68)$ & 0.02 \\
\hline NSDHL (protein) & $0.63(0.42-0.94)$ & 0.026 \\
\hline BLMH (protein) & $1.6(1-2.5)$ & 0.03 \\
\hline ALDH1A1 (protein) & $0.39(0.16-0.91)$ & 0.03 \\
\hline Age & $0.85(0.74-0.98)$ & 0.03 \\
\hline LGALS3BP (gene) & $7.1(1.2-43)$ & 0.032 \\
\hline LGALS3BP (protein) & $2.6(1.1-6.1)$ & 0.036 \\
\hline LGALS3 (gene) & $2.9(1-8.3)$ & 0.05 \\
\hline HAL (protein) & $1.4(1-2.1)$ & 0.05 \\
\hline RETREAT score & $2(0.94-4.3)$ & 0.074 \\
\hline THBS1 (protein) & $1.5(0.96-2.4)$ & 0.077 \\
\hline DTWD2 (gene) & $0.17(0.023-1.2)$ & 0.08 \\
\hline GSTA2 (gene) & $0.72(0.49-1)$ & 0.081 \\
\hline MGST1 (protein) & $0.67(0.42-1.1)$ & 0.094 \\
\hline HAL (gene) & $1.9(0.88-4.2)$ & 0.1 \\
\hline BLMH (gene) & $2.3(0.85-6)$ & 0.1 \\
\hline NQO2 (protein) & $0.57(0.29-1.1)$ & 0.11 \\
\hline NQO2 (gene) & $0.44(0.15-1.3)$ & 0.14 \\
\hline NSDHL (gene) & $0.045(0.00051-3.9)$ & 0.17 \\
\hline THBS1 (gene) & $1.7(0.79-3.5)$ & 0.18 \\
\hline GSTA2 (protein) & $0.83(0.62-1.1)$ & 0.19 \\
\hline AFP & $1(1-1)$ & 0.23 \\
\hline MGST1 (gene) & $0.55(0.2-1.5)$ & 0.24 \\
\hline microvascular invasion & $2.2(0.45-10)$ & 0.33 \\
\hline No. of tumors & $1.1(0.93-1.2)$ & 0.42 \\
\hline
\end{tabular}

The significant molecular and clinical variables are listed in bold $H R$ hazard ratio, $\mathrm{Cl}$ confidence interval

transcripts (ALDH1A1, LGALS3 and LGALS3BP) distinguish those patients with recurrence post-transplant from those who did not recur. These findings were orthogonally validated in an independent cohort of recipients transplanted for HBV-HCC beyond Milan. These analytes represent a potential prognostic immunohistochemical signature in HCC beyond Milan criteria.

Our combined proteomic/transcriptomic signature adds to the current knowledge on predicting recurrence post-LT in HCC beyond Milan criteria. Current predictors of HCC recurrence after LT have been limited to tumor burden on the explant, presence of vascular invasion, and elevated AFP, together comprising scores such as the RETREAT score, used to determine the frequency of surveillance for post-LT recurrence [35]. However, this cannot be used in pre-transplant decision making, as microvascular invasion is only confirmed by posttransplant explant histological assessment. This denotes the limitations of the current image-based only selection algorithm of HCC for LT. Additionally, the ability to predict recurrence is critical for a few reasons: first, those beyond Milan HCC with favourable molecular signatures could be considered for LT. Secondly, the risk-tobenefit ratio might not be in favour of transplant in those with poor molecular features. Those with a higher risk of recurrence would need to be considered for post-transplant surveillance.

We found that high expression of ALDH1A1 protein and transcript level in the primary HCC tumor was associated with lower rates of recurrence post-LT. The expression of ALDH1A1 has been reported as a favorable prognostic factor in HCC, being significantly associated in previous literature with low serum levels of alphafetoprotein, well-differentiated pathology and a favorable clinical outcome [36-38]. Similarly, ALDH1A1 had significantly downregulated phosphorylation in HCC compared to adjacent tissue [11]. Consistent with our results, in a gene ontology annotation study of the ALDH1 family [39], HBV-related HCC patients who showed high ALDH1L1 gene expression had superior clinical outcome, with a 57-month recurrence-free survival. High ALDH1B1 expression was protective for HCCs with multiple nodules and high serum alpha-fetoprotein level [39]. Guo et al. [40] have previously reported that long noncoding RNA MACC1-AS1 promoted the stemness of HCC cells by antagonizing ALDH1 [39]. Our study in the LT context is thus in keeping with previous literature on ALDH1A1 in non-transplant HCC.

ALDH1A1 catalyzes the oxidation of the retinol metabolite retinaldehyde to retinoic acid [33]. Thus, lower ALDH1A1 expression in our recurrent cases could represent reduced production of retinoic acid. In concordance, experimental evidence shows that retinoid activity is reduced in HCC cell lines. Moreover, patients with HCC display decreased hepatic retinoid stores and altered retinoid signaling [41]. Intriguingly, retinoic acid treatment inhibited LGALS3 expression in carcinoma cells [42], suggesting that reduced levels of retinoic acid could promote LGALS3 upregulation. In turn, increased levels of LGALS3 have been associated with a higher ability of the tumors to neutralize the immune system [32]. ALDH1A1 and LGALS3 were differentially expressed in opposite directions between recurrent and non-recurrent samples, and their expression strongly and negatively correlated with each other. In addition, we demonstrated a significant increase in the LGALS3/ALDH1A1 ratio in recurrent samples, as compared to non-recurrent samples. This finding may suggest that ALDH1A1 and LGALS3 are functionally related and contribute to HCC invasiveness, particularly in tumours with high LGALS3 relative to ALDH1A1 expression. 


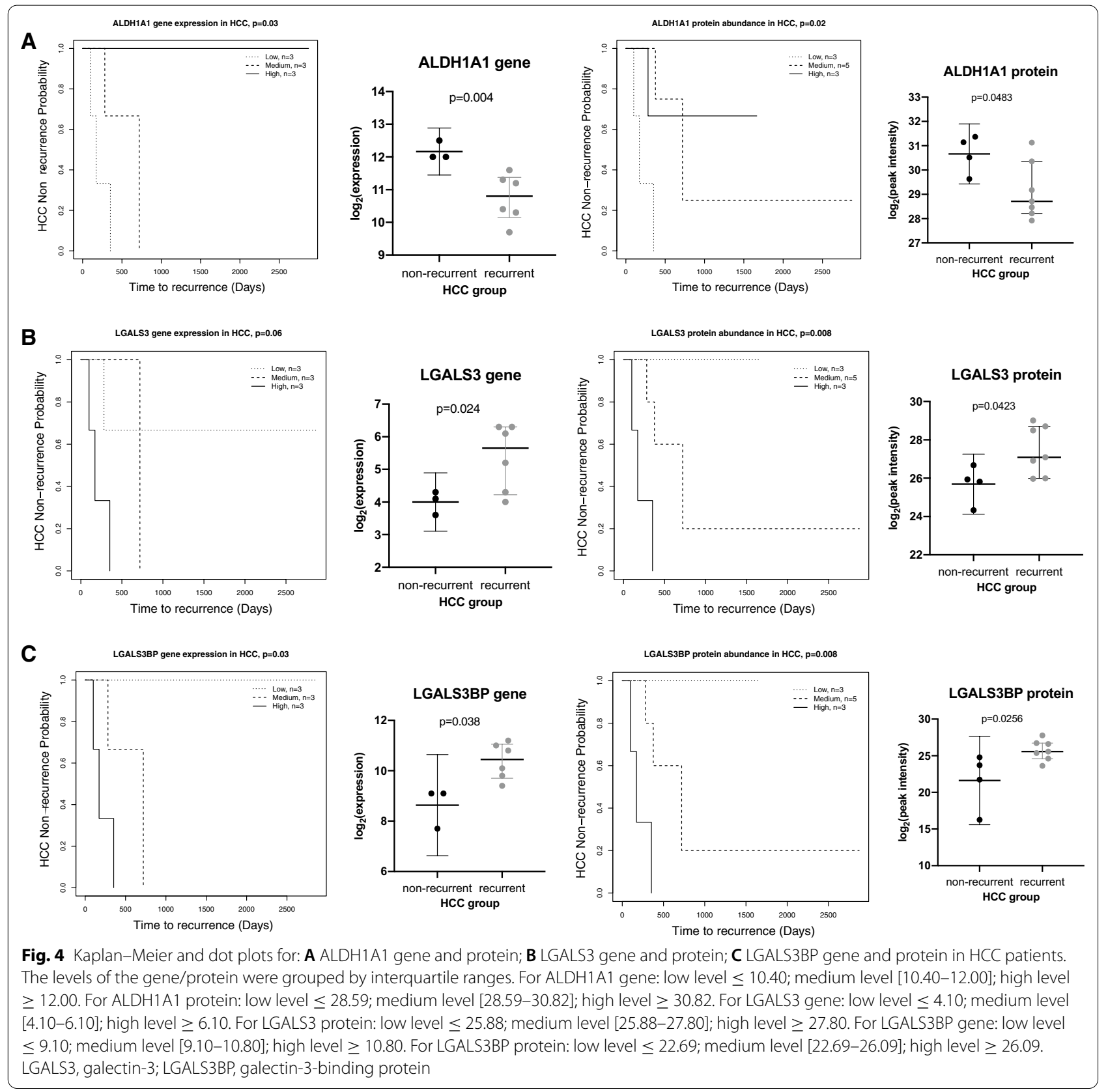

LGALS3 expression levels were directly associated with a higher risk of HCC recurrence post-transplant in our cohort. LGALS3 was reported to be critical for Ras signaling and thus supports mitogen activated protein kinase (MAPK) and AKT cascades. Increased levels of LGALS3 have been associated with a higher ability of the tumors to neutralize the immune system [43]. Along the same lines, LGALS3 protein expression was increased in HCC tumours, compared to adjacent tissue [11]. The same study demonstrated that both LGALS3 and LGALS3BP were significantly increased in more aggressive HCC tumours. Our survival investigation on an external HCC dataset from TCGA showed that, despite these samples representing a clinical context different from our own, the results were supportive, by revealing worse prognosis of tumors expressing high LGALS3 and LGALS3BP and low ALDH1A1. LGALS3BP interacts with LGALS3 and was found to be upregulated and highly correlated with LGALS3 in our study. Prior studies indicated that LGALS3BP can be used along with alpha-fetoprotein to improve the screening sensitivity for HCC [43]. LGALS3BP, together with CD5 antigen like (CD5L) 


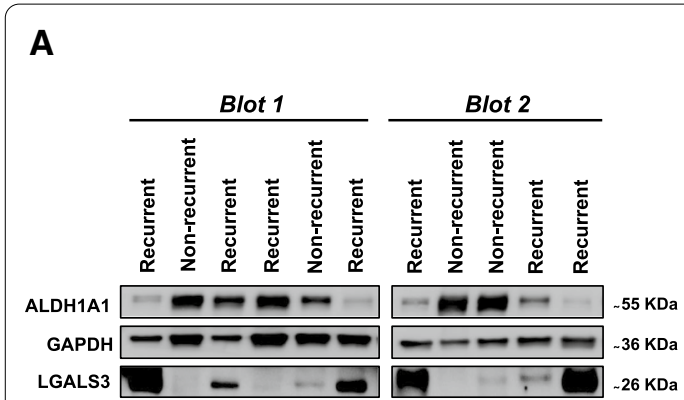

D

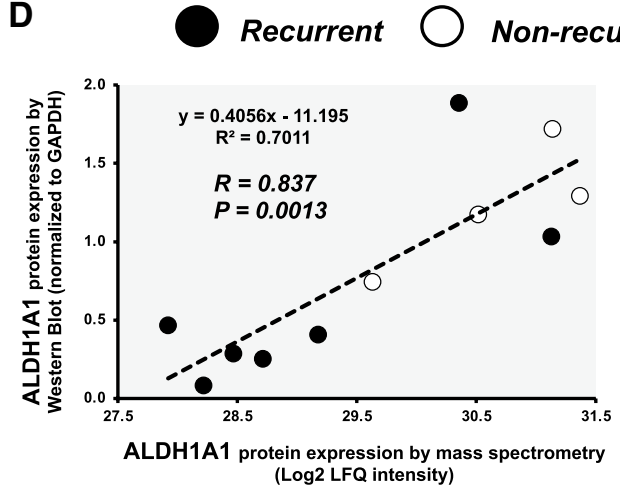

B

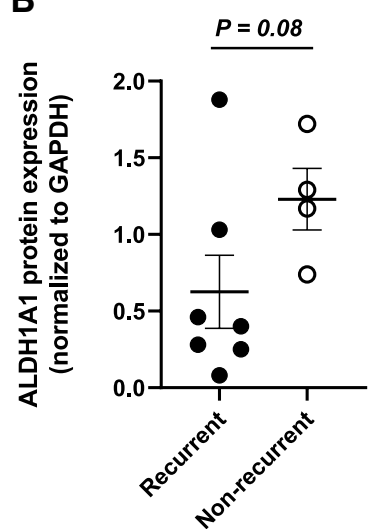

C

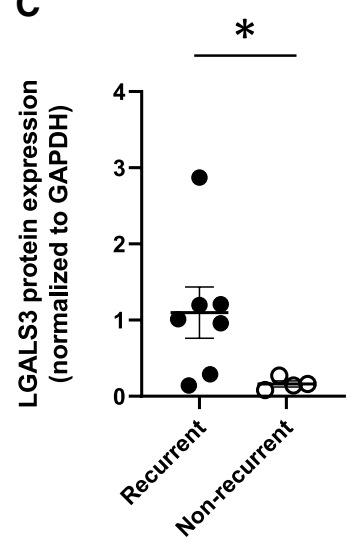

E
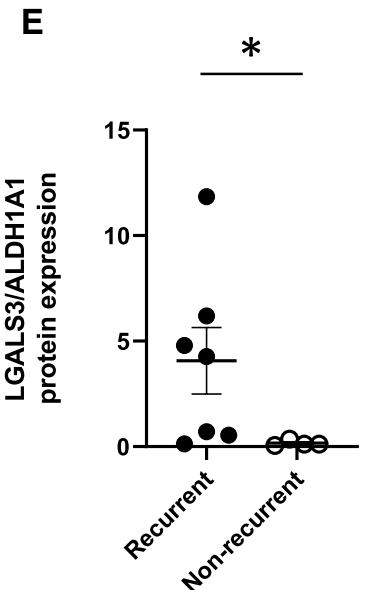

Fig. 5 Verification of ALDH1A1 and LGALS3 protein expression changes in HCC tumour explants. A Shows the immunoblot bands of ALDH1A1, LGALS3, and GAPDH in recurrent $(n=7)$ and non-recurrent $(n=4)$ HCC patients. Cropped images of the blots were used in order to improve the clarity and conciseness of the presentation. The protein expression of ALDH1A1 (B) and LGALS3 (C) were measured by densitometry and normalized to GAPDH. The Pearson correlations between Western Blot and mass spectrometry log2-transformed LFQ protein intensity values of ALDH1A1 and LGALS3 were evaluated (D). The Western blot LGALS3/ALDH1A1 ratio was also calculated (E). *P $<0.05$. Data are reported as mean \pm standard error. LFQ, label-free quantification; LGALS3, galectin-3; ALDH1A1, retinal dehydrogenase 1. LGALS3, galectin-3; LGALS3BP, galectin-3-binding protein; $\mathrm{ALDH1} A 1$, retinal dehydrogenase 1

and immunoglobulin J chain (IGJ) constituted a triplemarker panel predictive of poor HCC survival and rapid progression after sorafenib treatment [44]. LGALS3 and LGALS3BP are thus candidate proteins for identifying HCC tumours with increased likelihood for recurrence post-LT, which might represent potential therapeutic targets to diminish HCC recurrence post-LT [45].

Other studies have examined transcriptional markers of HCC recurrence post-LT. Miltiadous et al. [46] conducted a pivotal study examining gene expression profiling of HCC beyond the Milan Criteria and identified the progenitor phenotype (determined by either CK-19 expression or the Hoshida S2 signature) as predictive of post-LT recurrence. The S2 HCC subclass was linked to high levels of alpha-fetoprotein expression, activation of mTOR and IGF signaling, even at the early stages of the disease. This study certainly pinpointed potential gene signatures predictive of recurrence. Importantly, our study has extended this approach by generating a combined transcriptomic and proteomic signature predictive of HCC recurrence post-LT, which permits cost-effective immunohistochemical evaluation of a proteomic signature.

Our study had limitations. First, our sample size was limited, and it was not possible to adjust for significant clinical and pathological covariates such as tumor burden on explant, presence of microvascular invasion and AFP at time of transplant. Nonetheless, we included only samples from Hepatitis B-induced HCC, the most common reason for $\mathrm{HCC}$ liver transplant beyond Milan criteria, in order to minimize heterogeneity. This is a pilot study and additional studies with larger sample sizes and etiologies beyond hepatitis $B$ will be needed to validate our results. Additionally, with long pre-LT waiting times 


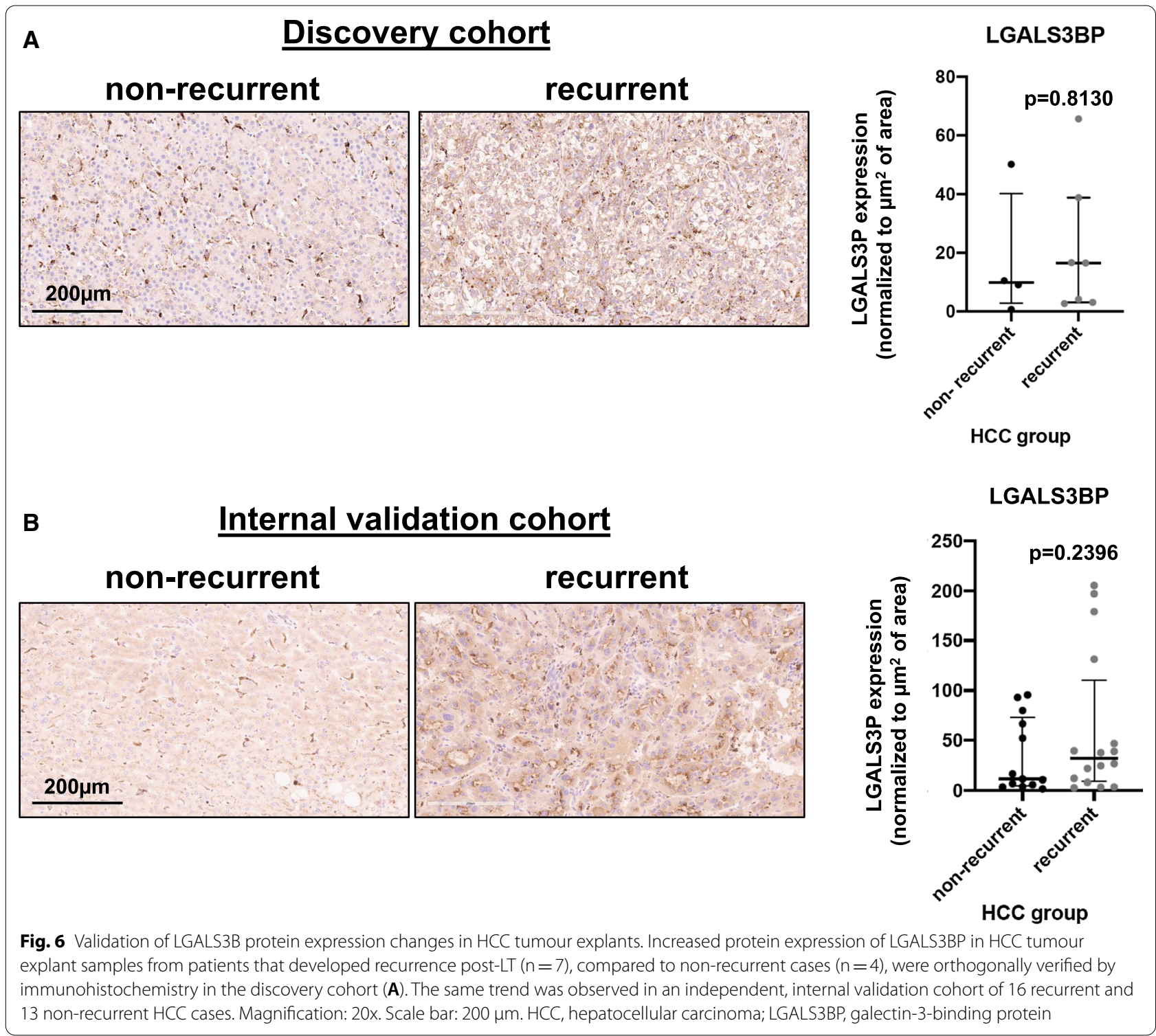

before transplantation and bridging therapy, the stability of tumor gene/protein expression profiles over time must be considered, should predictive signatures be incorporated into pre-LT patient selection. Despite these shortcomings, our observations provide an initial comprehensive and combined proteomic and transcriptomic profile of HCC explants for patients identified pre-LT beyond Milan criteria. Integration of high-throughput omics profiles is particularly powerful to decipher the key molecules involved in carcinogenesis [47-50]. Because expression profiling could be performed on liver needle biopsies in a pretransplant setting [51], the positivity of the proposed signatures might also assist in the decision making for selecting patients for transplantation.
In conclusion, we have derived an HCC explant protein signature comprised of ALDH1A1, LGALS3 and LGALS3BP to predict risk of HCC recurrence posttransplant. This short list of proteins was identified using both high-throughput proteomics and transcriptomics, and validated using immunohistochemistry and immunoblotting on HCC explant specimens. Staining of explant specimens for these 3 proteins could provide further guidance regarding screening protocols for patients transplanted for HCC beyond Milan. These findings support the possibility that molecular analysis of HCC performed prior to LT may enable expansion of the current imaging-based selection criteria to include patients beyond Milan Criteria with favorable 
molecular profiles, though this will require further investigation.

\section{Supplementary Information}

The online version contains supplementary material available at https://doi. org/10.1186/s12014-021-09333-x.

Additional file 1: Figure S1. Distribution of protein intensity values and principal component analysis of the HCC samples. Each histogram in panel A represents the distribution of the original log2 transformed LFQ intensity values among the proteins quantified in each of the 11 studied HCC tumor explant samples. Blue bars represent the count of intensity values determined by mass spectrometry. In panel B, red bars represent the distribution of the imputed intensity values. To evaluate the similarity across the proteomes of the studied samples, the distribution of variances of the $\log 2$ transformed LFQ intensity values of all quantified proteins were examined by principal component analysis using Perseus software (C). The tumor explant samples from LT patients with recurrent HCC are depicted in red, while the non-recurrent cases are represented in blue. LFQ, label-free quantification; LT, liver transplant; HCC, hepatocellular carcinoma.

Additional file 2: Figure S2. Correlation analysis between the immunoblotting and mass spectrometry-based protein levels of key proteins identified in this study. The Pearson correlation coefficients (R), as well as the significance of the correlation (P), were calculated for the following comparisons: LGALS3 vs. LGALS3BP protein intensity $(A, n=10)$, LGALS3 vs. ALDH1A1 protein intensity $(B, n=11)$, and ALDH1A1 vs. LGALS3BP protein intensity $(C, n=10) . P<0.05$ was considered statistically significant. $\mathrm{LFQ}$, label-free quantification; $\mathrm{ALDH1A1}$, retinal dehydrogenase 1, LGALS3, galectin-3; LGALS3BP, galectin-3-binding protein.

Additional file 3: Figure S3. Kaplan-Meier survival plots for: (A) ALDH1A1 gene and protein; (B) LGALS3 gene and protein; (C) LGALS3BP gene and protein in HCC patients. The levels of the gene/protein were grouped by mean. For ALDH1A1 gene: low level < 11.22; high level $>11.22$. For ALDH1A1 protein: low level <29.67; high level $\geq 29.67$. For LGALS3 gene: low level < 4.91; high level $\geq 4.91$. For LGALS3 protein: low level <26.60; high level $\geq 26.60$. For LGALS3BP gene: low level $<9.80$; high level $\geq 9.80$. For LGALS3BP protein: low level <23.48; high level $\geq 23.48$.

Additional file 4: Figure S4. Kaplan-Meier survival curves based on gene expression of: (A) ALDH1A1, (B) LGALS3 and (C) LGALS3BP in the TCGA HCC dataset. HR, hazard ratio; ALDH1A1, retinal dehydrogenase 1; LGALS3, galectin-3; LGALS3BP, galectin-3-binding protein.

Additional file 5: Table S1. Total number of proteins identified in each HCC explant sample before and after filtering.

Additional file 6: Table S2. Proteins significantly differentially expressed in HCC samples that go on to develop HCC recurrence compared to those that do not recur. NR, non-recurrence; $R$, recurrence.

Additional file 7: Table S3. Significantly enriched pathways among proteins differentially expressed between HCC samples developing recurrence compared to non-recurrent ones. Pathways are determined using pathDIP, and those with adjusted $p$-value $<0.05$ by Benjamini-Hochberg are included.

Additional file 8: Table S4. List of pathways associated with gene/proteins significantly increased in HCC explant samples that exhibited posttransplant recurrence. Table S5. List of pathways associated with genes/ proteins significantly decreased in HCC explant samples that exhibited post-transplant recurrence. Table S6. Clinical characteristics of the 29 patients transplanted for HCC beyond Milan criteria with versus without recurrence post-transplant. Median values are reported, and the $95 \%$ confidence intervals are displayed in the brackets.

\section{Acknowledgements}

Not applicable.

\section{Authors' contributions}

Concept and design: $M B, G S, A K$; Experiments and procedures: $M B, S C-F, C B$, $E P, A H, T I, S R, A A, M A, A G, S F, G S$, AK; Writing of the article: MB, SC-F, CB, EP, AH, GS, AK; Editing and revision of the article: MB, MA, GS, AK. All authors read and approved the final manuscript.

\section{Funding}

MB acknowledges support from the Canadian Liver Foundation, NSERC, American Society of Transplantation, Canadian Donation and Transplant Research Program, and the Toronto General and Western Hospital Foundation. AK is supported by Kidney Foundation of Canada Predictive Biomarker grant KFOC160010, the Canadian Institutes of Health Research (CIHR), Canada Foundation for Innovation (CFI) grant 37205, and Kidney Research Scientist Core Education and National Training (KRESCENT) program grants CIHR148204, KRES160004, and KRES160005. AK has also received funding from the Toronto General and Western Hospital Research Foundation (TGTWF 1617464; TGTWF MKFTR 1718-1268). SC-F is supported by the KRESCENT program (2019KPPDF637713).

\section{Availability of data and materials}

The transcriptomic data have been deposited to Gene Expression Ominibus (GEO) repository with the dataset identifier GSE164368. The mass spectrometry proteomics data have been deposited to the ProteomeXchange Consortium via the PRIDE [24] partner repository with the dataset identifier PXD022881 (Reviewer account details: Username: reviewer_pxd022881@ebi. ac.uk; Password: 2GmXJTJo).

\section{Declarations}

\section{Ethics approval and consent to participate}

Patients who underwent LT for hepatitis B-induced HCC beyond Milan criteria between 2004 and 2015 were included in our study. This protocol was approved by the University Health Network (UHN) Institutional Review Board (REB\#15-9989).

\section{Consent of publication}

Not applicable.

\section{Competing interests}

The authors declare that they have no competing interests.

\section{Author details}

${ }^{1}$ Ajmera Transplant Program, University Health Network, Toronto, Canada. ${ }^{2}$ Division of Gastroenterology and Hepatology, University of Toronto, Toronto, Canada. ${ }^{3}$ Toronto General Hospital Research Institute, Toronto, Canada.

${ }^{4}$ Department of General Surgery, Mansoura University, Mansoura, Egypt.

${ }^{5}$ Department of Laboratory Medicine and Pathology, University of Toronto, Toronto, Canada. ${ }^{6}$ Division of Multi-Organ Transplant and HPB Surgical Oncology, Department of General Surgery, University Health Network, Toronto, Canada. ${ }^{7}$ Institute of Medical Science, University of Toronto, Toronto, Canada. ${ }^{8}$ Division of Nephrology, Department of Medicine, University Health Network, Toronto, Canada. ${ }^{9}$ University Health Network, 585 University Avenue, Room 11-PMB-189, Toronto, ON M5G 2N2, Canada.

Received: 8 June 2021 Accepted: 3 November 2021

Published online: 18 November 2021

\section{References}

1. Global Burden of Disease Cancer C, Fitzmaurice C, Allen C, Barber RM, Barregard L, Bhutta ZA, et al. Global, regional, and national cancer incidence, mortality, years of life lost, years lived with disability, and disabilityadjusted life-years for 32 cancer groups, 1990 to 2015: a systematic analysis for the global burden of disease study. JAMA Oncol. 2017;3(4):524-48.

2. Yang JD, Larson JJ, Watt KD, Allen AM, Wiesner RH, Gores GJ, et al. Hepatocellular carcinoma is the most common indication for liver 
transplantation and placement on the waitlist in the United States. Clin Gastroenterol Hepatol. 2017;15(5):767-75.e3.

3. Mazzaferro V, Regalia E, Doci R, Andreola S, Pulvirenti A, Bozzetti F, et al. Liver transplantation for the treatment of small hepatocellular carcinomas in patients with cirrhosis. N Engl J Med. 1996;334(11):693-9.

4. Sapisochin G, Goldaracena N, Laurence JM, Dib M, Barbas A, Ghanekar $A$, et al. The extended Toronto criteria for liver transplantation in patient with hepatocellular carcinoma: a prospective validation study. Hepatology. 2016;64(6):2077-88.

5. Yao FY, Ferrell L, Bass NM, Watson JJ, Bacchetti P, Venook A, et al. Liver transplantation for hepatocellular carcinoma: expansion of the tumor size limits does not adversely impact survival. Hepatology. 2001;33(6):1394-403.

6. Mazzaferro V, Llovet JM, Miceli R, Bhoori S, Schiavo M, Mariani L, et al. Predicting survival after liver transplantation in patients with hepatocellular carcinoma beyond the Milan criteria: a retrospective, exploratory analysis. Lancet Oncol. 2009;10(1):35-43.

7. Toso C, Trotter J, Wei A, Bigam DL, Shah S, Lancaster J, et al. Total tumor volume predicts risk of recurrence following liver transplantation in patients with hepatocellular carcinoma. Liver Transpl. 2008;14(8):1107-15.

8. Duvoux C, Roudot-Thoraval F, Decaens T, Pessione F, Badran H, Piardi T, et al. Liver transplantation for hepatocellular carcinoma: a model including alpha-fetoprotein improves the performance of Milan criteria. Gastroenterology. 2012;143(4):986-94.e3 (quiz e14-5).

9. Mazzaferro V, Sposito C, Zhou J, Pinna AD, De Carlis L, Fan J, et al. Metroticket 2.0 model for analysis of competing risks of death after liver transplantation for hepatocellular carcinoma. Gastroenterology. 2018;154(1):128-39.

10. Cillo U, Giuliani T, Polacco M, Herrero Manley LM, Crivellari G, Vitale A. Prediction of hepatocellular carcinoma biological behavior in patient selection for liver transplantation. World J Gastroenterol. 2016;22(1):232-52.

11. Jiang $Y$, Sun $A$, Zhao $Y$, Ying $W$, Sun $H$, Yang $X$, et al. Proteomics identifies new therapeutic targets of early-stage hepatocellular carcinoma. Nature. 2019;567(7747):257-61.

12. Duda DG, Dima SO, Cucu D, Sorop A, Klein S, Ancukiewicz M, et al. Potential circulating biomarkers of recurrence after hepatic resection or liver transplantation in hepatocellular carcinoma patients. Cancers. 2020;12(5):1275

13. Xue F, Higgs BW, Huang J, Morehouse C, Zhu W, Yao X, et al. HERC5 is a prognostic biomarker for post-liver transplant recurrent human hepatocellular carcinoma. J Transl Med. 2015;13:379.

14. Yang Z, Zhu H, Zhang L, Wei Q, Zhou L, Xu X, et al. DNA methylation of SOCS1/2/3 predicts hepatocellular carcinoma recurrence after liver transplantation. Mol Biol Rep. 2020;47(3):1773-82.

15. Wu LM, Zhang F, Zhou L, Yang Z, Xie HY, Zheng SS. Predictive value of CpG island methylator phenotype for tumor recurrence in hepatitis B virus-associated hepatocellular carcinoma following liver transplantation. BMC Cancer. 2010;10:399.

16. Chen HY, Han ZB, Fan JW, Xia J, Wu JY, Qiu GQ, et al. miR-203 expression predicts outcome after liver transplantation for hepatocellular carcinoma in cirrhotic liver. Med Oncol. 2012;29(3):1859-65.

17. Sugimachi K, Matsumura T, Hirata H, Uchi R, Ueda M, Ueo H, et al. Identification of a bona fide microRNA biomarker in serum exosomes that predicts hepatocellular carcinoma recurrence after liver transplantation. Br J Cancer. 2015;112(3):532-8.

18. Gao S, Lin BY, Yang Z, Zheng ZY, Liu ZK, Wu LM, et al. Role of overexpression of MACC1 and/or FAK in predicting prognosis of hepatocellular carcinoma after liver transplantation. Int J Med Sci. 2014;11(3):268-75.

19. Li R, Gong J, Xiao C, Zhu S, Hu Z, Liang J, et al. A comprehensive analysis of the MAGE family as prognostic and diagnostic markers for hepatocellular carcinoma. Genomics. 2020;112(6):5101-14.

20. Caviglia GP, Ciruolo M, Olivero A, Carucci P, Rolle E, Rosso C, et al. Prognostic role of serum cytokeratin-19 fragment (CYFRA 21-1) in patients with hepatocellular carcinoma. Cancers. 2020;12(10):2776.

21. Clotet-Freixas S, McEvoy CM, Batruch I, Pastrello C, Kotlyar M, Van JAD, et al. Extracellular matrix injury of kidney allografts in antibody-mediated rejection: a proteomics study. J Am Soc Nephrol. 2020;31(11):2705-24.

22. Clotet S, Soler MJ, Riera M, Pascual J, Fang F, Zhou J, et al. Stable isotope labeling with amino acids (SILAC)-based proteomics of primary human kidney cells reveals a novel link between male sex hormones and impaired energy metabolism in diabetic kidney disease. Mol Cell Proteomics. 2017;16(3):368-85.

23. Van JAD, Clotet-Freixas S, Zhou J, Batruch I, Sun C, Glogauer M, et al. Peptidomic analysis of urine from youths with early type 1 diabetes reveals novel bioactivity of uromodulin peptides in vitro. Mol Cell Proteomics. 2020;19(3):501-17.

24. Perez-Riverol Y, Csordas A, Bai J, Bernal-Llinares M, Hewapathirana S, Kundu DJ, et al. The PRIDE database and related tools and resources in 2019: improving support for quantification data. Nucleic Acids Res. 2019;47(D1):D442-50

25. Rahmati S, Abovsky M, Pastrello C, Jurisica I. pathDIP: an annotated resource for known and predicted human gene-pathway associations and pathway enrichment analysis. Nucleic Acids Res. 2017:45(D1):D419-26.

26. Carvalho BS, Irizarry RA. A framework for oligonucleotide microarray preprocessing. Bioinformatics. 2010;26(19):2363-7.

27. Carvalho B. pd.hugene.2.0.st: Platform Design Info for Affymetrix HuGene2 0-st. R Package. 3.14.1 ed2015. p. Affymetirix HuGene 2.0.

28. Ritchie ME, Phipson B, Wu D, Hu Y, Law CW, Shi W, et al. limma powers differential expression analyses for RNA-sequencing and microarray studies. Nucleic Acids Res. 2015;43(7):e47.

29. Liu FT, Hsu DK, Zuberi RI, Hill PN, Shenhav A, Kuwabara I, et al. Modulation of functional properties of galectin-3 by monoclonal antibodies binding to the non-lectin domains. Biochemistry. 1996;35(19):6073-9.

30. Wang Y, Gao G, Wu Y, Wang Y, Wu X, Zhou Q. S100A4 silencing facilitates corneal wound healing after alkali burns by promoting autophagy via blocking the PI3K/Akt/mTOR signaling pathway. Investig Ophthalmol Vis Sci. 2020;61(11):19.

31. Therneau TM. A package for survival analysis in R; 2020. https://CRAN.Rproject.org/package=survival.

32. Farhad M, Rolig AS, Redmond WL. The role of Galectin-3 in modulating tumor growth and immunosuppression within the tumor microenvironment. Oncoimmunology. 2018;7(6):e1434467.

33. Tomita $\mathrm{H}$, Tanaka $\mathrm{K}$, Tanaka T, Hara A. Aldehyde dehydrogenase $1 \mathrm{~A} 1$ in stem cells and cancer. Oncotarget. 2016;7(10):11018-32.

34. Abdel Wahab AHA, El-Halawany MS, Emam AA, Elfiky A, Abd Elmageed ZY. Identification of circulating protein biomarkers in patients with hepatocellular carcinoma concomitantly infected with chronic hepatitis C virus. Biomarkers. 2017;22(7):621-8.

35. Mehta N, Heimbach J, Harnois DM, Sapisochin G, Dodge JL, Lee D, et al. Validation of a risk estimation of tumor recurrence after transplant (RETREAT) score for hepatocellular carcinoma recurrence after liver transplant. JAMA Oncol. 2017;3(4):493-500.

36. Ma S, Chan KW, Lee TK, Tang KH, Wo JY, Zheng BJ, et al. Aldehyde dehydrogenase discriminates the CD133 liver cancer stem cell populations. Mol Cancer Res. 2008;6(7):1146-53.

37. Suzuki E, Chiba T, Zen Y, Miyagi S, Tada M, Kanai F, et al. Aldehyde dehydrogenase 1 is associated with recurrence-free survival but not stem cell-like properties in hepatocellular carcinoma. Hepatol Res. 2012:42(11):1100-11.

38. Tanaka K, Tomita H, Hisamatsu K, Nakashima T, Hatano Y, Sasaki Y, et al. ALDH1A1-overexpressing cells are differentiated cells but not cancer stem or progenitor cells in human hepatocellular carcinoma. Oncotarget. 2015;6(28):24722-32.

39. Yang CK, Wang XK, Liao XW, Han CY, Yu TD, Qin W, et al. Aldehyde dehydrogenase 1 ( $\mathrm{ALDH} 1$ ) isoform expression and potential clinical implications in hepatocellular carcinoma. PLoS ONE. 2017;12(8):e0182208.

40. Guo Y, Zhong J, Wu F, Zhan Z. Long noncoding RNA MACC1-AS1 promotes the stemness of hepatocellular carcinoma cells by antagonizing miR-145. J Int Med Res. 2020;48(4):300060520920411.

41. Shirakami Y, Sakai H, Shimizu M. Retinoid roles in blocking hepatocellular carcinoma. Hepatobiliary Surg Nutr. 2015;4(4):222-8.

42. Lu Y, Amos B, Cruise E, Lotan D, Lotan R. A parallel association between differentiation and induction of galectin-1, and inhibition of galectin-3 by retinoic acid in mouse embryonal carcinoma F9 cells. Biol Chem. 1998;379(11):1323-31.

43. lacovazzi PA, Trisolini A, Barletta D, Elba S, Manghisi OG, Correale M. Serum 90K/MAC-2BP glycoprotein in patients with liver cirrhosis and hepatocellular carcinoma: a comparison with alpha-fetoprotein. Clin Chem Lab Med. 2001;39(10):961-5. 
44. Kim H, Yu SJ, Yeo I, Cho YY, Lee DH, Cho Y, et al. Prediction of response to sorafenib in hepatocellular carcinoma: a putative marker panel by multiple reaction monitoring-mass spectrometry (MRM-MS). Mol Cell Proteomics. 2017;16(7):1312-23.

45. Tummala KS, Brandt M, Teijeiro A, Grana O, Schwabe RF, Perna C, et al. Hepatocellular carcinomas originate predominantly from hepatocytes and benign lesions from hepatic progenitor cells. Cell Rep. 2017;19(3):584-600.

46. Miltiadous $\mathrm{O}$, Sia D, Hoshida Y, Fiel Ml, Harrington AN, Thung SN, et al. Progenitor cell markers predict outcome of patients with hepatocellular carcinoma beyond Milan criteria undergoing liver transplantation. J Hepatol. 2015;63(6):1368-77.

47. Hristova VA, Chan DW. Cancer biomarker discovery and translation: proteomics and beyond. Expert Rev Proteomics. 2019;16(2):93-103.

48. Cohen JD, Li L, Wang Y, Thoburn C, Afsari B, Danilova L, et al. Detection and localization of surgically resectable cancers with a multi-analyte blood test. Science. 2018;359(6378):926-30.
49. Zhang B, Wang J, Wang X, Zhu J, Liu Q, Shi Z, et al. Proteogenomic characterization of human colon and rectal cancer. Nature. 2014;513(7518):382-7.

50. Vogel C, Marcotte EM. Insights into the regulation of protein abundance from proteomic and transcriptomic analyses. Nat Rev Genet. 2012;13(4):227-32.

51. Hoshida Y, Villanueva A, Kobayashi M, Peix J, Chiang DY, Camargo A, et al. Gene expression in fixed tissues and outcome in hepatocellular carcinoma. N Engl J Med. 2008;359(19):1995-2004.

\section{Publisher's Note}

Springer Nature remains neutral with regard to jurisdictional claims in published maps and institutional affiliations.
Ready to submit your research? Choose BMC and benefit from:

- fast, convenient online submission

- thorough peer review by experienced researchers in your field

- rapid publication on acceptance

- support for research data, including large and complex data types

- gold Open Access which fosters wider collaboration and increased citations

- maximum visibility for your research: over $100 \mathrm{M}$ website views per year

At BMC, research is always in progress.

Learn more biomedcentral.com/submissions 